Acta Crystallographica Section A

Foundations of Crystallography

ISSN 0108-7673

Received 4 September 2007

Accepted 20 November 2007

(C) 2008 International Union of Crystallography

Printed in Singapore - all rights reserved

\section{High-pressure crystallography}

\author{
Andrzej Katrusiak‡ \\ Faculty of Chemistry, Adam Mickiewicz University, Grunwaldzka 6, 60-780 Poznań, Poland. \\ Correspondence e-mail: katran@amu.edu.pl
}

Since the late 1950's, high-pressure structural studies have become increasingly frequent, following the inception of opposed-anvil cells, development of efficient diffractometric equipment (brighter radiation sources both in laboratories and in synchrotron facilities, highly efficient area detectors) and procedures (for crystal mounting, centring, pressure calibration, collecting and correcting data). Consequently, during the last decades, high-pressure crystallography has evolved into a powerful technique which can be routinely applied in laboratories and dedicated synchrotron and neutron facilities. The variation of pressure adds a new thermodynamic dimension to crystal-structure analyses, and extends the understanding of the solid state and materials in general. New areas of thermodynamic exploration of phase diagrams, polymorphism, transformations between different phases and cohesion forces, structureproperty relations, and a deeper understanding of matter at the atomic scale in general are accessible with the high-pressure techniques in hand. A brief history, guidelines and requirements for performing high-pressure structural studies are outlined.

\section{Introduction}

X-ray structural diffraction studies revolutionized material sciences: chemists, physicists and biologists looked at their substances of interest at the atomic level (Pauling, 1939), which allowed them to understand the properties of matter and to predict new properties of other structures. Up to now, over half a million structures have been determined, most of them at ambient conditions and at low temperature. The justification for performing structural analyses at ambient conditions is very simple - we live and apply most materials at ambient conditions ( $c a .295 \mathrm{~K}$ and $0.1 \mathrm{MPa}){ }^{\mathbf{1}}$

Conditions that are considerably different from those of the human environment are described as extreme conditions. The development of science and technology increasingly relies on technologies involving extreme conditions, like extrusion of metal capillaries, syntheses of super-hard materials (Huppertz, 2004; Kim et al., 2007), production of components of jet engines and spacecraft coatings, and also in the search for new polymorphic forms of drugs (Boldyreva, Shakhtshneider, Ahsbahs, Sowa \& Uchtmann, 2002; Boldyreva, Shakhtshneider, Ahsbahs, Uchtmann et al., 2002), pigments and energetic materials (Fabbiani \& Pulham, 2006). For many years, variation of temperature has been the main manner of changing thermodynamical conditions in technological processes and structural studies. Of all 404800 organic and

\footnotetext{
\# In memory of Dr Igor Goncharenko $(1965-2007)$.
${ }^{1}$ The SI pressure units, Pascal $=$ Newton metre
-2 $\left(\mathrm{Pa}=\mathrm{N} \mathrm{m}^{-2}\right)$, are used in this paper. The atmospheric pressure at sea level is approximately $0.1 \mathrm{MPa}=$ 1 bar.
}

organometallic structures deposited in the Cambridge Crystallographic Database Centre (CCDC, 5.28 Version released in January 2007), 134405 structures were measured below $283 \mathrm{~K}$ (40546 below $150 \mathrm{~K}, 1517$ below $90 \mathrm{~K}$ and 82 below $5 \mathrm{~K}$ ), and only 596 above $303 \mathrm{~K}$. There are various reasons for lowering temperature in structural investigations, mainly as a routine procedure to reduce atomic thermal vibrations and obtain more precise structural data, or to investigate phase transitions and low-temperature phases, or to crystallize and analyse substances which are liquid, gaseous or unstable at normal conditions. Some studies were performed as a function of other thermodynamical variables, like chemical composition or electrical field. Only about 100 structures of organic compounds deposited in CCDC were determined at elevated pressure. The number of CCDC entries with the pressure descriptor in 2007 (350 entries) doubled from 2005 (174 entries) and tripled from 2000 (123 entries). Although a larger number of elements, minerals and inorganic compounds were studied at high pressures, the fraction of all crystals investigated at elevated pressure is still very low.

Initially, those most interested in matter at high-pressure conditions were geoscientists and astrophysicists. Most of the matter of Earth and of the Solar System is exposed to very high pressure. For example, the pressure at the centre of the Earth is estimated as $364 \mathrm{GPa}$, in Saturn $2500 \mathrm{GPa}$, in Jupiter $4000 \mathrm{GPa}$ and in the Sun $15000000 \mathrm{GPa}$, not to mention the neutron stars (about $10^{26} \mathrm{GPa}$ ). Geoscientists are interested in the formation of rocks and minerals, their high-pressure phases, compressibility, dynamics of transformations at earthquakes, and propagation of seismic waves. Pressure is 
highly efficient for generating phase transitions and new phases, for triggering new chemical reactions, conformational and structural transformations of molecules, polymerization, phase transitions, polymorphism and structure-property relations, which are of interest to chemists and physicists. The knowledge of stability of substances at extreme conditions is still far from complete: it is difficult to generally predict pressure-generated reactions and transformations. Many of them are relevant to materials sciences or geosciences. For example, gas hydrates stable at high pressure (Kuhs, 2004; Dyadin et al., 1994; Shimizu et al., 2002) constitute most of the carbon fuels on Earth, and the composition of the Earth's core and the interiors of large planets still remain to be investigated. It is generally believed that at sufficiently high pressures all substances become metallic; in some substances, pressure can induce superconductivity (e.g. boron, lithium, silicon, sulfur, oxygen) and enhance or suppress superconductivity in others (Gauzzi et al., 2004; Hemley, 1998; Edvards \& Hensel, 1997; Struzhkin et al., 1997). Transformations of protein structures and their high-pressure stabilization are of interest to biologists (Kundrot \& Richards, 1986; Katrusiak \& Dauter, 1996; Barciszewski et al., 1999; Kunz, 2001; Gruner, 2004; Fourme et al., 2004; Girard et al., 2007).

It is now apparent that pressure can considerably contribute to a better understanding of many condensed-phase phenomena, and in numerous projects researchers naturally progress toward high-pressure experiments (Hemley \& Ashcroft, 1998). One of the best-known examples is the stability of $\mathrm{H}_{2} \mathrm{O}$ ice: at ambient pressure, only hexagonal $P 6_{3} / m m c$ phase $I h$ and cubic $F d 3 m$ symmetric phase $I c$ are known to be stable to lowest temperatures, ${ }^{2}$ while at elevated pressures ten other phases have been discovered (Lobban et al., 1997).

Meanwhile, for years, high-pressure structural studies were hindered by technical difficulties, caused by the access to the sample through the thick walls of the environment vessels. Thus, in most high-pressure experiments macroscopic properties of substances were measured (Bridgman, 1949), whereas diffraction studies were scarce and required large and cumbersome installations (Kabalkina \& Vereshchagin, 1960; Kabalkina \& Troitskaya, 1961).

The most remarkable breakthrough in high-pressure research was triggered by the invention of the diamond-anvil cell in 1958 (Jamieson et al., 1959; Weir et al., 1959). Other inventions and discoveries made in high-pressure methodology soon followed. Now researchers have convenient methods for generating pressure, which can be applied for various probing techniques in their laboratories and dedicated beamlines in synchrotron and neutron facilities (Hazen \& Finger, 1982; Eremets, 1996; Holzapfel \& Isaacs, 1997; Katrusiak \& McMillan, 2004). Indeed, following the inception of the diamond-anvil cell (DAC) and developments of X-ray diffraction techniques, the number of structural determina-

\footnotetext{
${ }^{2}$ Ice $I h$ doped with $\mathrm{KOH}$ at $72 \mathrm{~K}$ transforms following the onset of the H-atom ordering (Kawada, 1972) to the orthorhombic polar structure, space group $C m c 2_{1}$, often described as ice phase XI (Line \& Whitworth, 1996; Jackson $t$ al., 1997).
}

tions at high pressures steadily increases every year. The DAC is also used to perform complementary studies, like electric conductivity, magnetism (Goncharenko, 2004), optical, Raman, IR, X-ray absorption, Mössbauer (Pasternak et al., 2004) and NMR (Lee et al., 1987; Bertani et al., 1990, 1992) spectroscopies. At the same time, the development of diffractometers and high-pressure methodology over the last decades considerably facilitated the high-pressure experiments. The principal aim of this paper is to summarize selected achievements of high-pressure crystallography, to present some details of the high-pressure equipment that can be installed in most X-ray diffraction laboratories, and to exemplify some of possible structural transformation induced by pressure in crystals.

\section{Some facts about the diamond-anvil cell (DAC)}

\subsection{Historical background}

In hindsight, the construction of the DAC appears very simple and its operation obvious. It is amazing that such a small, plain and elegant device is capable of generating the highest static pressures achieved in a laboratory. Moreover, it seems that all the knowledge necessary for the DAC invention was known and published by P. W. Bridgman. ${ }^{\mathbf{3}} \mathrm{He}$ formulated the principle of massive support (Bridgman, 1937), constructed the opposed-anvils apparatus (so called Bridgman anvils) capable of generating a pressure of $10 \mathrm{GPa}$ (Bridgman, 1950, 1952), and used a pipestone gasket for sealing and preventing extrusion of the sample from between the anvils. However, his anvils were large and made of carboloy (tungsten carbide cemented in cobalt), a material very hard and heat-resistant but in many respects inferior to diamond. Other milestones that led to the DAC invention were:

(i) application of diamond in high-pressure devices (Lawson \& Tang, 1950; Jamieson, 1957);

(ii) designs of the opposed-diamond-anvils cell (DAC) (Jamieson et al., 1959; Weir et al., 1959);

(iii) application of a metal gasket in the DAC for obtaining hydrostatic pressure conditions (van Valkenburg, 1962);

(iv) invention of the ruby-fluorescence method for pressure calibration (Forman et al., 1972).

There were a considerable number of other very important developments, without which the DAC would not be such a versatile apparatus as it is today (for reviews, see Hazen \& Finger, 1982; Jayaraman, 1983; Ahsbahs, 1987; Eremets, 1996; Holzapfel \& Isaacs, 1997; Katrusiak \& McMillan, 2004).

\subsection{The key issue of right materials}

The heart of any DAC is built of diamond. For ages, diamond has been known as the hardest material and assigned the highest grade of 10 on the Mohs scale. However, the jump to the next-hardest on the Mohs scale, corundum (grade 9), is

\footnotetext{
${ }^{3}$ Percy Williams Bridgman (1882-1961), a Professor of Harvard University in Cambridge, Massachusetts, dedicated his research to high-pressure physics, thermodynamics and philosophy; in 1946, he was awarded the Nobel Prize for his achievements in high-pressure research.
} 
a large one (Brazhkin et al., 2002). On the Knoop hardness scale, diamond is several times harder than corundum - on this absolute scale, the hardness of corundum is much closer to that of talc and graphite (grade 1 on the Mohs scale) than to diamond; and the resistance of diamond to abrasion (about 140000 on the Rosiwal scale) is over two orders of magnitude higher than that of corundum (1000). Thus, with respect to its hardness, diamond is the most suitable material for highpressure cell construction. It also has other advantages: low absorption of short X-rays, linear absorption coefficient $\mu_{\text {diamond }}($ Mo $K \alpha)=0.202 \mathrm{~mm}^{-1}$, excellent transparency for visual radiation, and good transparency for UV and IR wavelengths (type IIA diamonds with low nitrogen content). Although diamonds are considered expensive, the cost of a

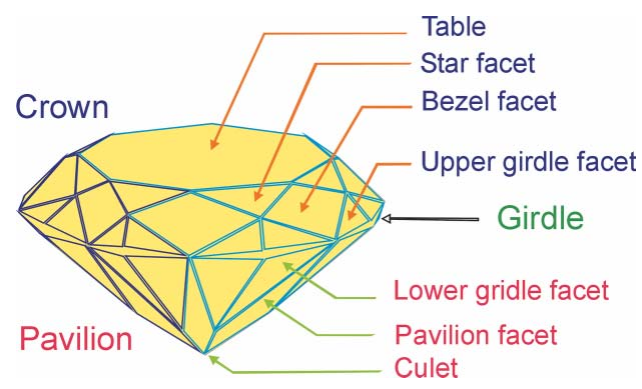

Figure 1

The brilliant-design diamond anvil, with the names of its parts and facets indicated. Flat culets with 8 or 16 edges are polished for high-pressure anvils.

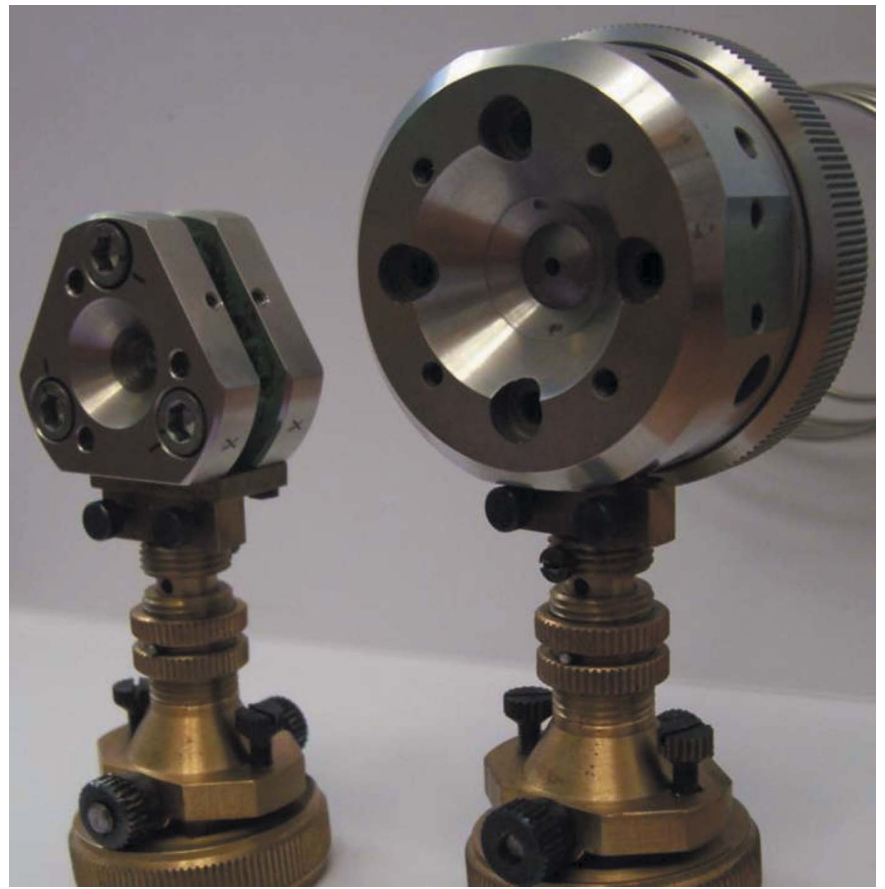

Figure 2

Diamond-anvil cells mounted on goniometer heads: a Merrill-Bassett DAC (Merrill \& Bassett, 1974) with steel backing plates of anvils (left) and a gas-membrane DAC with hemispherical beryllium backing plates (right). Behind the membrane cell, the capillary for operating the membrane is visible. typical DAC for X-ray diffraction, equipped with flawless $\frac{1}{4}$ carat brilliant anvils, amounts to a mere few percent of that of either a low- or a high-temperature attachment.

The DAC is a unique construction of the most advanced apparatus of its kind, ingenious and elegant in its simplicity, the most essential parts of which were well known to nearly everyone - the flawless brilliants like those in rings or jeweller's shops (Fig. 1). For X-ray diffraction applications, the diamond anvils are often mounted on beryllium discs, which in turn are centred in a steel vice with conical windows, like in a miniature Merrill-Bassett cell shown in Fig. 2 (Merrill \& Bassett, 1974). The linear absorption coefficient for beryllium is very low for molybdenum radiation, $\mu_{\mathrm{Be}}(\mathrm{Mo} K \alpha)=$ $0.048 \mathrm{~mm}^{-1}$, however the beams passing through the discs increase the background, produce powder diffraction rings and beryllium softens at about $500 \mathrm{~K}$, which hampers applications at high temperature. Beryllium is also expensive and its oxide is poisonous. Therefore, the anvils are often mounted directly on the steel edges of the conical windows (Konno et al., 1989). The central hole in the beryllium disc or the conical window in the steel backing plates give convenient access for optical observations and spectroscopic measurements. The small volume of the DAC chamber eliminates any risk of explosions, associated with much larger cylinder-and-piston devices.

Up to today, flawless low-birefringence type IA $\frac{1}{4}$ carat ( 1 carat $=0.2 \mathrm{~g}$ ) brilliant diamonds with a phased culet are most often used in DAC's (Fig. 1). In fact, the anvils of the first DAC's were gems confiscated from smugglers by customs agents and donated for research purposes (Piermarini, 2001). Other than brilliant shapes of diamond anvils have been designed in order to reduce the strains (which could result in failure of the anvils when generating pressure) or to facilitate mounting of the anvils. Some of these designs are illustrated in Fig. 3. In the standard Drukker anvil, its shape has been simplified and the table surface increased (Seal, 1984); the Boehler-Almax anvil was optimized for supporting its crown section on the precisely matching tungsten carbide backing plate (Boehler \& De Hantsetters, 2004; Boehler, 2006); another design with the specially made anvils mounted on the crown section was described by Ahsbahs (2004). For pressures up to about $5.0 \mathrm{GPa}$, ordinary brilliant anvils supported on the crown facets by a steel backing plate (Fig. 4) are used in our laboratory. Diamond plates were also used for supporting

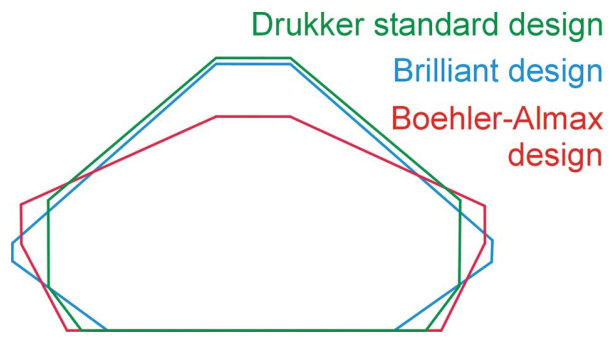

Figure 3

Overlaid cross-section contours of three designs of diamond anvils: Drukker standard (green), brilliant (blue) and Boehler-Almax (red). 
the anvils (Yamanaka, Fukuda et al., 2001), and perforated diamond anvils are made for reducing absorption in Mössbauer spectroscopy (Dadashev et al., 2001). For Mbar pressures (above $100 \mathrm{GPa}$ ), bevelled culets reduce the stress concentration on the culet edges (Mao \& Bell, 1978; Seal, 1984).

The DAC's are small - they can be mounted on stable goniometer heads (Fig. 2) and used for experiments with standard laboratory X-ray diffractometers (Fig. 5).

\subsection{Principles of the DAC operation}

The axial thrust produced by the DAC vice mechanism is transmitted to the large tables and crown edges of two opposed diamond anvils, and through the stressed anvils to the culets. The pressure exerted on the tables is multiplied by the factor of the ratio of the surface area of the supported table side to the culet surface, and squeezes the gasket and sample contained in the high-pressure chamber. For table and culet diameters of 3.0 and $0.7 \mathrm{~mm}$, respectively, the ratio is $3.0^{2} / 0.7^{2} \approx 20$, and to obtain the multiplication factor of $100 \mathrm{a}$ $0.3 \mathrm{~mm}$ culet diameter would be required.

The chamber diameter is usually equal to half or less of that of the culet. Like in the seals designed by Bridgman, the pressure exerted by the culets on the gasket exceeds that in the pressurized sample, so the closure is self-sealing. The hardness of the gasket and anvil materials increases under compression. These principles of the DAC operation are the same in all designs, although they can be considerably modified for specific applications and adapted to the requirements of different probing methods. For the purpose of this paper, we will focus on X-ray diffraction crystallographic experiments, although DAC's are also used for high-pressure optical spectroscopy (IR, UV-VIS, Raman, NMR) and for other physical experiments, chemical reactions, syntheses of new materials, biological observations, and even as precision cuvettes in forensic investigations. The DAC is an ideal micro reaction chamber allowing optical observation of chemical transformations at many GPa pressures and varied temperatures (Nicol \& Yin, 1984) - the progress in analytical methods allows successful characterization of minute amounts of

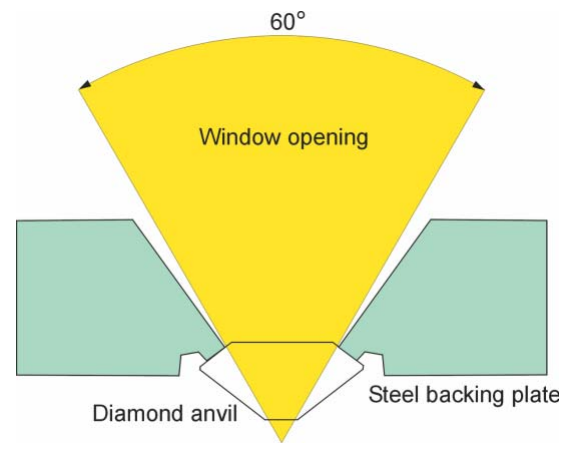

Figure 4

The effective access to the sample for laboratory X-ray diffraction measurements, illustrated for a brilliant-cut anvil, the crown facets of which are supported on the edges of the window in the steel backing plate. products synthesized in this way. Pressure-induced transformations can be investigated in non-hydrostatic conditions when a substance is squeezed between the DAC culets (Fig. 6) and in hydrostatic conditions when the investigated substance is contained in a liquid (Fig. 7).

It follows from the massive support principle that a conical anvil can support a compressive stress $n K$, where $K$ is the yield stress of the anvil material and $n$ equals 1.0 for cylindrical anvils (semi-cone angle $\xi$ equal to $0^{\circ}$ ) and 3.0 for $\xi$ equal to $90^{\circ}$. The anvil culet is further supported by the plastically deformable gasket, which extrudes around the sloped pavilion to diameter $D_{\text {ext }}$, larger than the diameter of the culet, $D$, and additionally increases attainable pressure to $P=2 K \ln \left(D_{\text {ext }} / D\right)$ (Yousuf \& Rajan, 1982; Dunstan, 1989; Dunstan \& Spain, 1989).

\subsection{DAC types and designs}

There have been various DAC designs, optimized for the measurement technique, sample requirements and other thermodynamical conditions (low or high temperature). X-ray diffraction can be performed on single crystals and powders (Meade \& Jeanloz, 1990; McMahon, 2004; Parise, 2004), as well as on intermediate cases of 'bad powders' with large crystalline grains. Only the DAC's for diffraction studies will be briefly classified and exemplified below. Laboratory X-ray diffractometers and those used at synchrotron beamlines considerably differ too (Prewitt et al., 1987; Mao et al., 1988; Nelmes et al., 1992; Fiquet \& Andrault, 1999; Crichton \& Mezouar, 2004; Katrusiak, 2004a). At synchrotrons, very intense X-ray beams can be collimated to a few micrometres, thus the problem of the beam shadowing by the gasket is

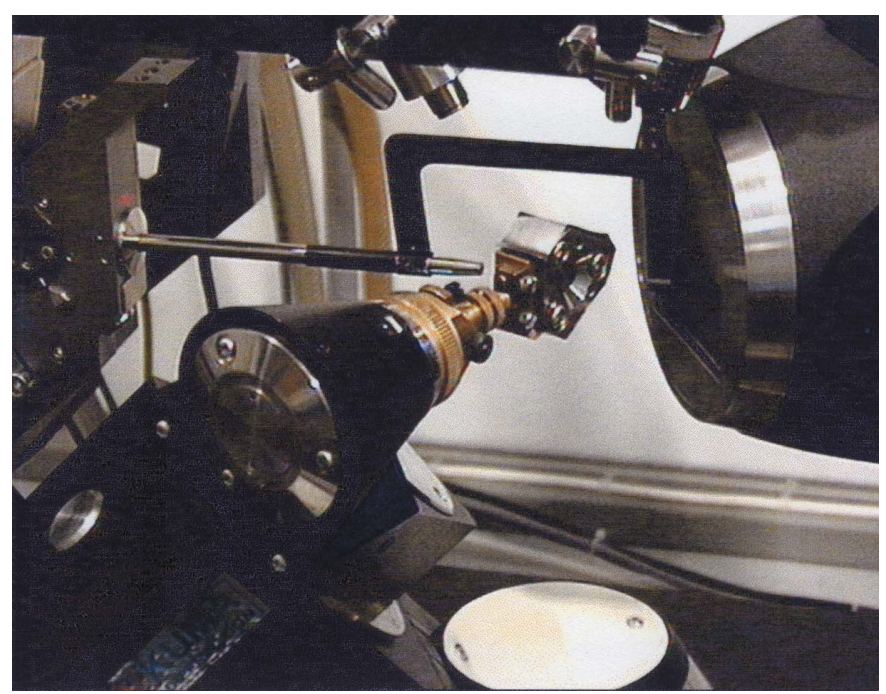

Figure 5

A Merrill-Bassett diamond-anvil cell, mounted on a stable goniometer head on a four-circle $\kappa$ diffractometer KUMA KM4-CCD during a data collection in the $\phi=0^{\circ}$ and $\omega$-scan mode. To reduce the level of radiation scattered on the diamonds, beryllium plates and gasket, the gap between the DAC parts is shielded with a metal strip; additionally, lead-loaded glass shielding (not shown here) encloses the diffractometer for security reasons. 
considerably reduced; the huge intensity of the beam allows efficient and quick experiments to be performed by the powder method on very small samples, which allows experiments at very high pressures and varied temperatures; by applying very short wavelengths (of about $0.3 \AA$ ), one can considerably increase the completeness of accessible data; and owing to the low divergence of the beam and large sampledetector distance the overlapping ratio of powder diffraction rings in the powder experiments is minimized.

The advantage of laboratory set-ups is that they allow one to perform high-pressure studies with no restrictions in the countries and institutions that have restricted access to synchrotrons. At present, single-crystal X-ray diffraction is the easiest technique to implement and the most precise method for studying crystal structure at elevated pressure in a laboratory. Most X-ray laboratories are equipped with singlecrystal angle-dispersive diffractometers, which can be easily adapted to high-pressure studies.

Generally, elastic scattering studies can be classified into monochromatic and polychromatic methods, and also as angledispersive and energy-dispersive, and single-crystal and powder techniques. All these methods are applied in structural studies. In the energy-dispersive set-up, the polychromatic beam is

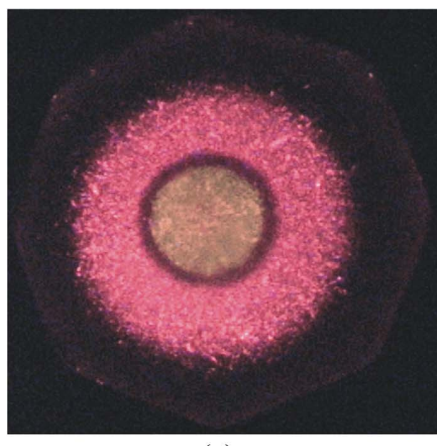

(a)

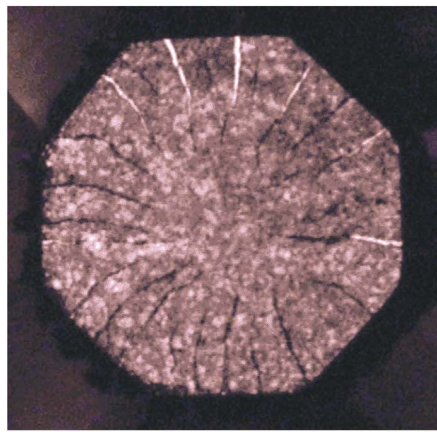

(c)

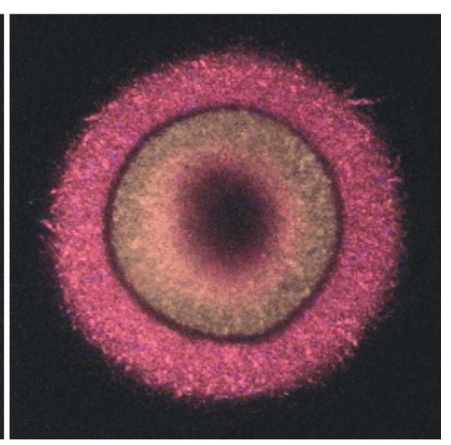

(b)

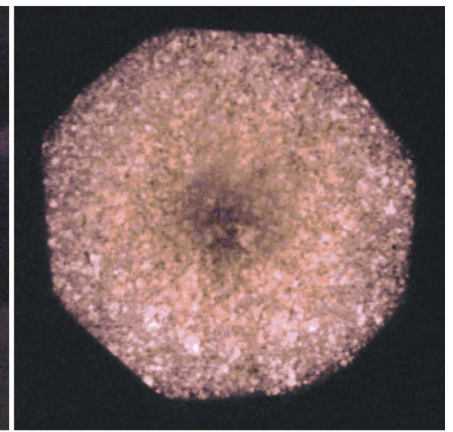

(d)
Figure 6

Samples of $(a, b) \mathrm{HgI}_{2}$ and $(c, d)$ palladium dimethyl glyoxime uniaxially squeezed between DAC culets, with the stress increased from the left to right photographs. The colour changes in $\mathrm{HgI}_{2}$ mark phase III (to $0.4 \mathrm{GPa}$ ), phase IV (to $1.3 \mathrm{GPa}$ ), phase VI (to $7.6 \mathrm{GPa}$ ) and phase VII at the centre of the right photograph (Hostettler \& Schwarzenbach, 2005). Continuous colour change occurs without structural phase transitions in palladium dimethyl glyoxime (Tkacz \& Drickamer, 1986). The culet diameter (octagon contours close to the edge of the photographs) is $0.7 \mathrm{~mm}$. diffracted on the powdered sample and at a given direction an energy-discriminating detector measures the intensity of reflections. This is convenient for high-pressure measurements because only narrow windows are required for the primary and diffracted beams. Energy-dispersive techniques are often used for powder X-ray diffraction measurements in laboratories, and also for neutron powder diffraction (time-of-flight method). However, the angle-dispersive methods are more precise for X-rays, and most X-ray laboratories are equipped with angle-dispersive diffractometers, for both single-crystal and powder diffraction. Angle-dispersive powder diffraction is superior to single-crystal studies in this respect because a complete set of data can be measured for a given DACwindow opening. Moreover, the single crystal may be difficult to grow, can be fragile and is often destroyed at phase transitions, and powder diffraction facilitates studies of transformations of such materials. The diffracted beams from small powder samples are very weak and therefore this method is preferably used at synchrotron facilities. However, powder diffraction with DAC may pose some difficulties due to the small size of the sample (few powder grains) and preferred orientation in the compressed or recrystallized powder.

The construction of the DAC vice (i.e. the thrust-generating mechanism) is adjusted to the applied diffraction method. The DAC's for angle-dispersive diffraction measurements are usually classified: (i) according to the positions of the windows for the incident and diffracted beams, as: transmission (Merrill \& Bassett, 1974; Keller \& Holzapfel, 1977) and transverse (Schiferl, 1977; Malinowski, 1987; Ahsbahs, 1987); (ii) according to the thrust-generating mechanism as: lever-arm (Weir et al., 1959), (2-, 3-, 4- etc.) screws and gliding bolts (Merrill \& Bassett, 1974), double lever (Keller \& Holzapfel, 1977), or inflatable membrane (Chervin et al., 1995); (iii) according to the range and method of controlling temperature as: cryogenic, externally/internally/laser heated DAC's; and (iv) according to other specific features and applications, like magnetic field transparent, for IR, NMR, Mössbauer spectroscopies, or a miniature DAC for four-circle diffractometers and cryostats.

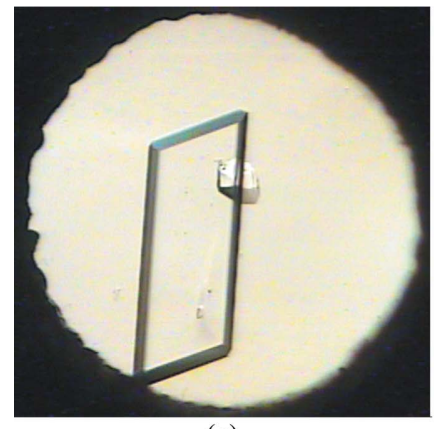

(a)

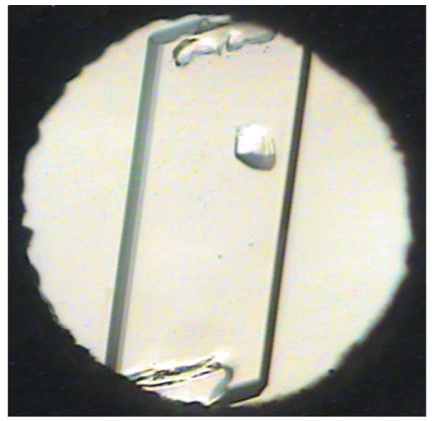

(b)
Figure 7

Two stages of ethynylbenzene isothermal freezing viewed down the DAC axis (Dziubek et al., 2007). The ruby chip for pressure calibration is visible above the centre of the cell. The diameter of the chamber is $0.4 \mathrm{~mm}$ and its height is $0.15 \mathrm{~mm}$. 
Most of the DAC's used for diffractometric studies operate in transmission mode, when the primary beam enters the pressure chamber through one of the anvils and the reflection leaves through the opposite anvil. Other modes of the DAC operation are also possible: a transverse mode, when the primary and diffracted beams pass through the same diamond anvil (Malinowski, 1987), and perpendicular mode, when the beams pass through the gasket (Ahsbahs, 1987). The advantage of the transmission DAC's is that they are very simple, allow a convenient optical insight into the chamber, minimize the gasket shadowing and are convenient in operation. All DAC's consist of two blocks made of steel (or another strong alloy) in various ways supporting the diamond anvils, and of a mechanism for generating the thrust between them (three screws in the Merrill-Bassett cell and a membrane in the membrane cell shown in Fig. 2).

\section{Pressure generation in the DAC}

\subsection{Choosing gasket, hydrostatic fluid, diamonds and DAC}

Depending on specific measurement - the planned range of pressure, sample solubility, strength and scattering power etc.appropriate DAC design, gasket, hydrostatic fluid and other experimental details can be chosen. For most routine singlecrystal high-pressure experiments in the pressure range to about $5 \mathrm{GPa}$, a miniature DAC designed by Merrill \& Bassett (1974) is a very convenient choice (Fig. 4); the gasket can be made of $0.25 \mathrm{~mm}$ steel, tungsten or hard alloy foil, with a hole diameter of $0.30-0.40 \mathrm{~mm}$ when diamond culets of $0.7-0.8 \mathrm{~mm}$ in diameter are used. The choice of the hydrostatic fluid depends on its pressure of solidification and on the solubility of the sample crystal (Piermarini et al., 1973; Angel et al., 2007).

\subsection{Pressure generation}

Pressure is generated when the DAC chamber filled with the sample and hydrostatic fluid is sealed and squeezed between the anvils and deformed gasket, as shown in Fig. 8. Generally, it is difficult to predict exactly how the gasket would deform when squeezed between the culets. However, the attainable pressure strongly depends on the applied dimensions of the culets and gasket. The main strength of the high-pressure chamber relies on the gasket contained between the culets, as the strongly compressed gasket material is much harder than at atmospheric pressure and the gasket surfaces are strongly supported owing to their large friction against the pressing culets. On the other hand, the thickness of the gasket (height of the DAC chamber, $h$ ) is inversely proportional to the attainable pressure, as the force acting on the gasket wall is proportional to its surface (Fig. 8). Thus one can draw a simplified diagram, shown in Fig. 9, of the attainable pressure depending on the ratio of $2 h /(D-d)$, where $h$ is the height of the pressure chamber, $D$ is the culet diameter and $d$ is the diameter of the high-pressure chamber.

The plots in Fig. 9 also illustrate that one can modify the chamber dimensions during experiments by so-called pressure cycling. In this technique, one increases pressure to a certain point, after which pressure is released (partly or completely) and increased again. In this new cycle, the starting chamber dimensions are modified. Moreover, many metals and alloys exhibit the work-hardening property and increase their strength when deformed several times.

Also, another technique, called pre-indentation of the gasket, is commonly applied (the blue arrow on the abscissa axis in Fig. 9). In some laboratories, the blank (not drilled) gasket is pre-indented in the DAC, after which the hole is drilled at the centre of the indentation (Hazen \& Finger, 1982; Miletich et al., 2000). Then the gasket is re-mounted in the DAC in exactly the same orientation. The pre-indentation increases the strength of the gasket material, allows the chamber dimensions to be adjusted (thickness of the foil), and improves the chamber sealing at the initial stages of pressure generation. A simpler reverse sequence of pre-indenting is also applied (Katrusiak, 1999): first the hole is drilled and then the gasket is centred on the diamond culet with the sample crystal and ruby chip already mounted, then gently pressed with the second anvil to check centring, and then after filling the chamber with hydrostatic fluid an air bubble is left inside and the gasket is squeezed. The air bubble allows control over the chamber sealing and allows one to reduce the diameter of the chamber by the plastic compression of the gasket. Then a cycling procedure can be applied, as described above.

Because of the large forces applied on the hard gasket material, the edges of the anvils are exposed to very high stress and can break when generating pressure above $10 \mathrm{GPa}$ - in such experiments, bevelled culets should be used to avoid damage of the anvils (Mao \& Bell, 1978; Seal, 1984).

\subsection{Pressure calibration}

The determination of pressure in the DAC chamber posed a considerable problem for several years after the DAC was invented: the chamber volume was very small, and the range of attainable pressures exceeded by over an order of magnitude the pressures obtained by any static methods before. Pressure in the DAC cannot be assessed from the applied load because it is difficult to predict the distribution of forces and plastic and elastic deformations in the DAC mechanical parts, in the anvils and their backing plates, and in the gasket. The pressure assessed in this way was usually highly inaccurate (e.g. Brash, 1965a,b; Bujak et al., 2004; Bujak \& Katrusiak, 2004). Other methods developed and used for calibrating pressure in the DAC are briefly described below.

Fixed-point scale based on the known freezing and solidsolid phase-transition pressures of internal standards, such as $n$-decane (m.p. $=0.30 \mathrm{GPa}$ at $300 \mathrm{~K})$, chloroform $(0.54 \mathrm{GPa})$, $n$-hexane (1.04 GPa), ethanol $(2.22 \mathrm{GPa}), \mathrm{Si}\left(T_{\mathrm{c}}=12.5 \mathrm{GPa}\right.$ at $300 \mathrm{~K}), \mathrm{ZnSe}, \mathrm{ZnS}, \mathrm{GaP}$ and $\mathrm{NaCl}(30.0 \mathrm{GPa})$. Several of the initially accepted points (those without pressures given here) proved highly inaccurate later (Piermarini \& Block, 1975; Piermarini, 2001).

Internal diffraction standard allows the pressure determination from the known equation of state. The diffraction 
pattern of a small single crystal or powder of the standard is measured simultaneously with that of the sample. This is a convenient method for powder studies and single-crystal experiments using two-dimensional detectors. In the case of point-detector diffractometers, the single-crystal internal standard required tedious separation and indexing of the standard and sample reflections (not to mention those from the diamond anvils) and re-measuring them in order to obtain required accuracy of the unit-cell-volume determination, which could consume one or two days for a single pressure point. With the CCD detector, the automatic indexing procedure of reflections occasionally produces the unit cell of ruby (used as the fluorescent standard; see below) as the first choice, instead of that of the sample investigated. Highsymmetry strongly scattering crystals without phase transitions in the required pressure range can be used, for example $\mathrm{NaCl}$ (below 29.5 GPa), $\mathrm{CsCl}$ (to $30.0 \mathrm{GPa}$ ), $\mathrm{CaF}_{2}$ (to $9.5 \mathrm{GPa}$ ) or quartz $\left(\mathrm{SiO}_{2}\right)$ or $\mathrm{MgO}$ (Yagi, 1985; Birch, 1986; Angel, 1993; Angel et al., 1997). For megabar domain and for hightemperature studies, powders of $F m \overline{3} m$ and $\operatorname{Im} \overline{3} m$ symmetric metals (Au, Pt, Pd, Al) can be used (Bell et al., 1986).

Fluorescence techniques considerably facilitated the pressure calibration for crystallographic experiments. In this method, a small chip of the calibrant is placed inside the DAC chamber, and then the pressure-induced change of its characteristic fluorescence band measured spectroscopically. Most often used for this purpose is the measurement of batochromic

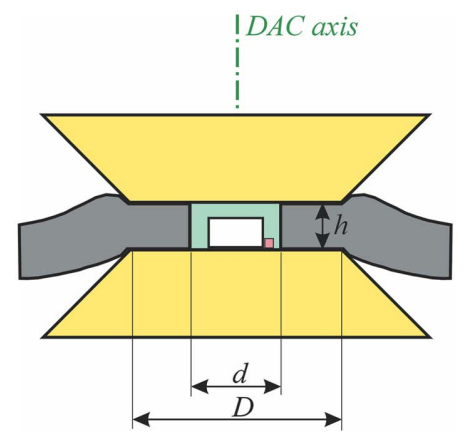

(a)

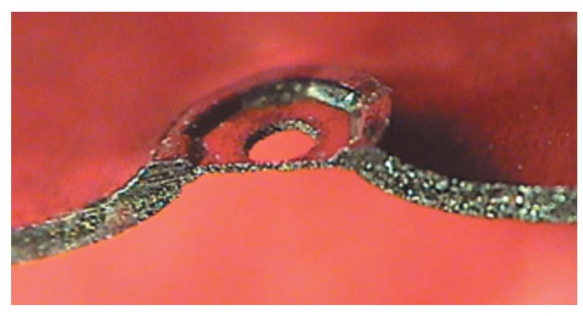

(b)

\section{Figure 8}

(a) The DAC high-pressure chamber containing a sample crystal (white), a calibration standard (pink) and filled with the hydrostatic fluid (blue); and $(b)$ the photographed cross section through the used gasket made of Inconel-alloy foil, $0.2 \mathrm{~mm}$ thick, squeezed to about $0.03 \mathrm{~mm}$ with $0.75 \mathrm{~mm}$ culets. The indentation of the gasket increases its compressed area, like in bevelled anvils. The dimensions indicated in drawing $(a)$ are: $h$ chamber height, $d$ chamber diameter, $D$ culet diameter.
$R_{1,2}$-doublet shift, $\Delta \lambda$, in the ruby fluorescence (at $c a 6942$ and $6927 \AA$, with small differences up to a few $\AA$ depending on the ruby sample); the pressure $-\Delta \lambda$ relation is linear to nearly $20 \mathrm{GPa}$ in the form: $\Delta p=0.2740(16) \times \Delta \lambda \mathrm{GPa}, \Delta \lambda$ in $\AA$ (Forman et al., 1972; Barnett et al., 1975; Piermarini et al., 1975); a quasi-linear relation in the form $\Delta p=1904\left[\left(\lambda / \lambda_{0}\right)^{B}-\right.$ $1] / B$, where $B$ is 7.655 for quasi-hydrostatic compression and 5 for nonhydrostatic compression, extends the ruby fluorescence scale to $180 \mathrm{GPa}$ (Bell et al., 1986). The measurement of the $R_{1,2}$ shift is quick and can be performed with a typical Raman spectrometer or with commercially available small spectrometers especially designed for pressure calibration, and a small green laser (second harmonic of a YAG $4 \mathrm{~mW}$ laser is used in our laboratory). Other optical pressure sensors are also in use. The $R_{1}$ line shift is temperature dependent $\left(\Delta \lambda / \Delta p=0.068 \AA \mathrm{K}^{-1}\right)$, which can cause systematic errors for overheated samples. In another pressure sensor, $\mathrm{SrB}_{4} \mathrm{O}_{7}: \mathrm{Sm}^{2+}$, the emission line at $6854 \AA$ is narrower than in ruby, hardly temperature dependent $\left(\Delta \lambda / \Delta p=0.001 \AA \mathrm{K}^{-1}\right)$, and $\Delta p=$ $0.3922 \Delta \lambda \mathrm{GPa}, \Delta \lambda$ in $\AA$ (Lacam \& Chateau, 1989; Leger et al., 1990; Datchi et al., 1997).

Infrared pressure gauges were devised to facilitate highpressure IR spectroscopy. In the 1960's, IR spectroscopy became popular for high-pressure research, but the introduction of laser excitation made Raman spectroscopy on small samples more efficient; then commercialized Fourier-transform spectrometers with fast-response detectors revived the IR pressure studies. The pressure gauges devised for IR studies in DAC are dilute ca $3 \%$ solutions of nitrite or nitrate ions in sodium bromide (Klug \& Whalley, 1983). Recently, it was shown that quartz mode $795 \mathrm{~cm}^{-1}$ can be used as a pressure sensor to about $20 \mathrm{GPa}$ (Chervin et al., 2005).

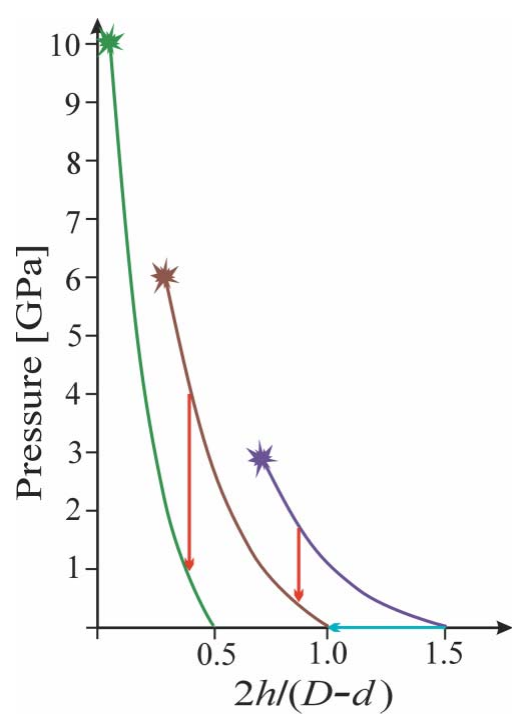

Figure 9

Relation between the initial high-pressure chamber dimensions $h, D$ and $d$ combined into the $2 h /(D-d)$ abscissa and pressure generated by deforming the gasket (see Fig. 8); the approximate attainable pressures are marked with small explosion signs. The blue horizontal arrow shows the changes in the chamber dimensions by the gasket pre-indentation and the red arrows indicate the pressure changes by cycling pressure. 


\subsection{Data correction}

The intensity of reflections from the crystal enclosed in the DAC should be corrected for Lorentz-polarization effects, the absorption of the DAC windows, absorption of the crystal itself, and shadowing of the sample crystal by the gasket (Hazen \& Finger, 1982; Kuhs et al., 1996; Angel et al., 2000; Katrusiak, 2004b,c). Computer programs for applying these corrections have been written and are applied (Kuhs et al., 1996; Katrusiak, 2001, 2004b; Angel, 2004). When data with high redundancy are available, it is also possible, by checking the consistency of the Bragg angles and intensities of symmetry-equivalent reflections measured at varied positions of the DAC (and different $\psi$ angles), to identify the reflections 'colliding' with the edges of the windows, superimposed with the diamond reflections, or weakened by the simultaneous diffraction effects in the sample and one or two diamond

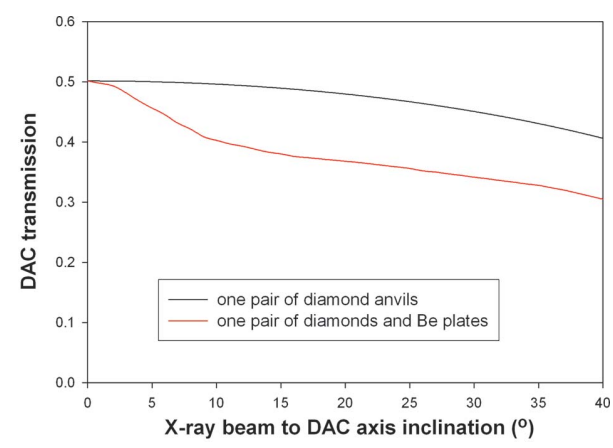

Figure 10

The transmission of a DAC equipped with two diamond anvils, each $1.7 \mathrm{~mm}$ high, mounted directly on the steel backing plates (black), and the same anvils mounted on $3.2 \mathrm{~mm}$ high Be plates, with centrally drilled $1.0 \mathrm{~mm}$ diameter holes (red).

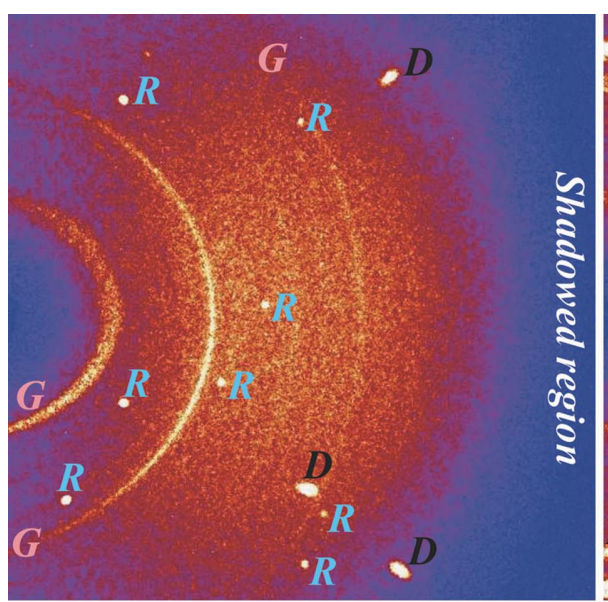

(a)

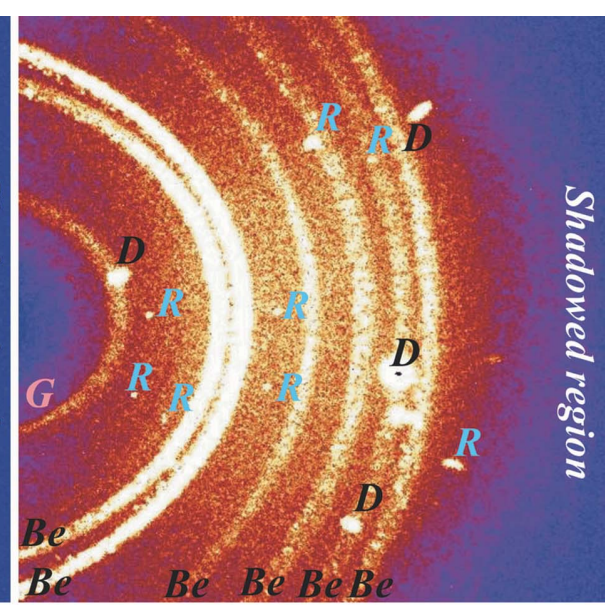

(b)
Figure 11

CCD images of a crystal of ethynylbenzene $\left(\mathrm{C}_{6} \mathrm{H}_{5} \mathrm{C} \equiv \mathrm{CH}\right.$, Fig. 7) at $0.40 \mathrm{GPa}$, recorded on a KUMA KM4 CCD diffractometer, Mo $K \alpha$ radiation, with the DAC positioned in the $\phi=0^{\circ}$ mode and $\omega$ scans of $0.75^{\circ}$ : (a) the DAC with the diamonds mounted on the steel edges of the backing plates ( $c f$. Fig. 4$)$; and (b) the same substance in the DAC with beryllium backing plates. The sample-crystal reflections are indicated with letters $R$, powder rings from the steel gasket with letter $G$; beryllium-powder rings with letters $\mathrm{Be}$; and diamond reflections with letter $D$. anvils (Loveday et al., 1990). The $R_{\text {int }}$ factor calculated after applying the corrections is a good measure of the quality of the corrected data. These data can be used like ordinary data, albeit only partly complete, for further stages of crystallographic calculations.

The application of the DAC with beryllium supporting plates for the anvils increases the background and somewhat lowers the transmission of the DAC (Figs. 10 and 11). On the other hand, the opening angle of the DAC with anvils supported on the edges of steel conical windows usually has a considerably smaller access for the beams onto the sample and a reduced completeness of the data that can be recorded.

\subsection{Structure solution from high-pressure data}

High-pressure data sets of reflection intensities recorded for low-symmetry sample crystals enclosed in the DAC are usually partly incomplete (Merrill \& Bassett, 1974), as illustrated in Fig. 12. Generally, the completeness of data depends on the Laue-group symmetry of the sample crystal, its orientation, and window openings of the DAC, as explained above. For cubic crystal samples, and hexagonal or tetragonal crystals oriented with [001] direction perpendicular to the DAC axis, the completeness can approach $100 \%$. The completeness of data attainable from one experiment decreases with decreasing Laue-class symmetry of the sample, and for triclinic samples can be lower than 30\%. Nonetheless, standard methods of solving the structure can be applied, like the Patterson search or direct methods. Despite incomplete data for orthorhombic, monoclinic and triclinic samples, direct methods yielded correct solutions for all organic crystals investigated in our laboratory. For example, the new highpressure ethynylbenzene triclinic phase, space group $P \overline{1}$ with $Z=6$ and 24 symmetry-independent carbon atoms (Dziubek et al., 2007), and the orthorhombic polymorph of 1,4-diazabicyclo[2.2.2] octane bromide, space group $\mathrm{Cmc2}_{1}$ (Budzianowski \& Katrusiak, 2006 b), were solved straightforwardly by direct methods.

It appears that the toroidal distribution of accessible reflections from the sample enclosed in the DAC encompasses the reflections involved in the triple invariant relations and suffices for determining the reflection phases in this subset. The triple relations combine the reflections with indices $\mathbf{h}_{1}=\left(h_{1} k_{1} l_{1}\right)$, $\mathbf{h}_{2}=\left(h_{2} k_{2} l_{2}\right)$ and $\mathbf{h}_{1} \pm \mathbf{h}_{2}=\left(h_{1} \pm h_{2}\right.$, $\left.k_{1} \pm k_{2}, l_{1} \pm l_{2}\right)$. In reciprocal space, the nodes that are linear combinations of $\mathbf{h}_{1}$ and $\mathbf{h}_{2}$ are confined to the plane determined by vectors $\mathbf{h}_{1}$ and $\mathbf{h}_{2}$. Thus such invariant relations can be formed for the planes of reciprocal-space nodes. The set of such 
planes of nodes, which are inclined to the DAC axis by less than half of the angle of the DAC window-opening cones, approximate the toroidal region accessible for the DAC. Moreover, for most $\mathbf{h}_{1}$ and $\mathbf{h}_{2}$ vectors in all of the accessible toroidal region, their sum $\mathbf{h}_{1}+\mathbf{h}_{2}$ is contained in this region, too. Thus the shape of the reciprocal-space-accessible region is favourable for direct methods, and this is reflected in the successful application of direct methods in high-pressure structural analyses.

\section{X-ray diffraction measurements with the DAC}

\subsection{From analogue to digital two-dimensional detectors}

The first single-crystal high-pressure X-ray diffraction measurements with a DAC were performed by using a Buerger precession camera and diffraction patterns recorded photographically - the high-pressure studies on crystalline $\mathrm{H}_{2} \mathrm{O}$ ice VI (Block et al., 1965) and chloroform (Fourme, 1968) were measured in this way. The recording of photographs on the precession camera requires that the crystal be precisely oriented such that the reciprocal plane be parallel to the film (one of the reciprocal vectors preferably along the precession axis and another vertical). The alignment of a bare crystal on the precession camera was accomplished in several steps. First, the crystal was mounted on a goniometer head in the approximately aligned position, then the crystal was more precisely adjusted by observing it through a microscope, and finally by performing a preliminary precession photograph from which final precise adjustments could be measured. The alignment of the crystal in the DAC was more difficult because of the limited possibility of controlling the orientation of the crystals in the DAC (particularly those grown by pressure freezing) and difficult microscopic observation of the crystal on the camera. After aligning the crystal in the DAC, a Lauecone photograph and a few accessible reciprocal-lattice sections (perpendicular to the DAC axis) could be recorded. These data were sufficient for determining the crystal symmetry and the position and orientation of small molecules and ions in the crystal structure.

In the mid 1970's automatic four-circle diffractometers were applied to high-pressure single-crystal X-ray diffraction studies (Merrill \& Bassett, 1974). The diffractometers were equipped with scintillation detectors and the measurement consisted of several stages. The crystal centring was performed optically with the aid of a microscope. The main difficulty was caused by the viewing of the crystal sample being restricted to one direction along the DAC axis. Thus the optical centring of the sample was difficult and usually was not precise. Any further steps required that the orientation matrix of the crystal (UB matrix) be determined. For finding the initial set of reflections, either a rotation photograph was made or a peakhunting procedure performed. Then the reflections had to be indexed and the UB matrix could be determined and refined (Busing \& Levy, 1967). With the UB matrix determined, one could refine the crystal centring by applying the diffractometric centring technique, which is much more reliable than the optical centring for the DAC. In the diffractometric technique, the corrections in the crystal position are derived from the offsets of the reflection positions. In the original version of the method, the selected reflections were measured at four or eight equivalent positions (Hamilton, 1974; King \& Finger, 1979) and more recently a general procedure based on an arbitrary set of reflections was developed (Dera \& Katrusiak, 1999). After centring the crystal, the UB matrix could be re-determined and more reliable unit-cell dimensions obtained. This was very important because the crystal positioning errors and restricted access to the reciprocal lattice of the sample often considerably lowered the precision of the UB matrix and affected the measurements of reflection intensities.

The accessible reflections were measured one by one. Whereas a bisecting mode of data collection was applied for bare crystal samples (i.e. the $\omega$ axis fixed at the $0^{\circ}$ position, where the $\chi$ circle bisected the angle formed by the incident and reflected beams in the diffraction plane), Finger \& King (1978) showed that for the DAC the so-called $\phi=0^{\circ}$ positioning mode (when the DAC axis lies in the diffraction plane) minimizes the DAC absorption and maximizes the access to the reciprocal-lattice nodes. The time required for measuring each reflection had to be extended considerably (usually by a factor of 5-10 compared to routine measurements carried out for bare crystals) because of the DAC absorption and high background of the radiation scattered on the beryllium discs, gasket and diamonds.

Several other DAC types, operating in both transmission and transverse geometries, were developed for the diffractometer measurements (e.g. Denner et al., 1978), however the

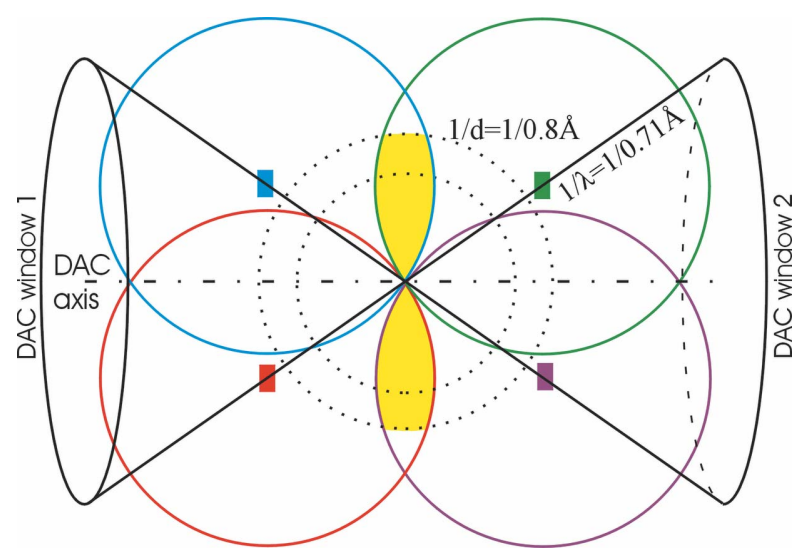

Figure 12

A geometrical construction illustrating the reciprocal-lattice region accessible for a crystal enclosed in the DAC. Two windows of the DAC and its axis (dash-and-dot line) are superimposed with four reciprocallattice Ewald spheres corresponding to four limiting positions of beams entering the DAC along four window edges (along the upper-left edge: purple circle; along bottom-left edge: green; along upper-right edge: red; and along bottom-right edge: blue; the centres of the circles are marked with rectangles in the corresponding colours representing the crystal positions). The yellow area marks the accessible area of the reciprocal lattice - the accessible region in three dimensions is a torus obtained by rotating this area about the DAC axis. A DAC windows opening of $70^{\circ}$ and molybdenum wavelength have been depicted to scale in this construction; the dotted circles correspond to the resolution of $0.80 \AA$ (larger) and $0.94 \AA$ (smaller). 
heavy cells required a sophisticated mounting on the diffractometer and often required difficult crystal-mounting and DAC-centring procedures.

\subsection{CCD detector era}

The development of two-dimensional electronic detectors for X-ray diffractometers soon prompted their use for highpressure studies (Piltz et al., 1992; Shimomura et al., 1992; Allan et al., 2000; Shobu et al., 2001; Crichton \& Mezouar, 2004; Ahsbahs, 2004). In several respects, the application of diffractometers equipped with a CCD camera considerably simplified the high-pressure experiments.

After initial difficulties with sample centring, a highly efficient automatic gasket-shadow method was developed (Budzianowski \& Katrusiak, 2004; Angel, 2004; Dawson et al., 2004). The UB-matrix determination prior to the data collection is not necessary because the CCD camera records the diffraction images, which can be analysed after the experiment. The UB-matrix determination is easier when all the data are available. Owing to the two-dimensional detector, the data collection is much faster than by using the scintillation detector, and usually a considerable redundancy of the data is obtained. The redundancy of the data allows several important systematic errors to be eliminated by comparing reflection intensities, such as those caused by overlaid reflections from the sample and from the diamonds or ruby standards, by the primary and diffracted beams truncated on the DAC window edges, and by weakening of the beams by simultaneous diffraction events on the sample crystal and diamond anvils. Inspection of images is very helpful for verifying the intensities of outlier reflections. 'Blind measurements' on new phases are possible when one is not certain if a new synthesized product or a new phase has been obtained, and the unit-cell and symmetry determination can all be performed after completing the data collection.

On the other hand, owing to the simultaneous recording of reflections and absence of one diffraction plane associated with the instrument, the reflections are not recorded precisely at the optimal DAC position. Approximately optimal DAC positioning can be obtained by maintaining the $\phi=0^{\circ}$ positioning mode (Budzianowski \& Katrusiak, 2004), however this can be done only on four-circle diffractometers (three-axis crystal orienter plus the $\theta$-axis detector positioner) made by several manufacturers. Meanwhile, CCD diffractometers with three axes only ( $\omega$ axis and $\phi$ spindle at a fixed $\chi$ angle, and the detector axis) have become very common, but the completeness and quality of high-pressure data measured on such instruments is considerably lower.

\subsection{High-pressure neutron diffraction studies}

High-pressure neutron diffraction constitutes another branch of high-pressure crystallography, which appeared and developed during the last decades (McWhan, 1984; Bloch \& Voiron, 1984; Voiron \& Vettier, 1987; Miletich et al., 2000; Goncharenko, 2004; Somenkov, 2005). The neutron diffraction can provide significant complementary information in many structural problems, for example when protons have to be located precisely, when the structure investigated contains very heavy elements, when nuclei with a similar number of electrons have to be distinguished, when magnetic structures are investigated, and also for inelastic scattering experiments. The main difficulty in these experiments is a relatively low intensity of neutron sources, reactors or spallation sources, compared even to the intensity of the X-ray beam from conventional sealed tubes, not to mention synchrotrons, and the scattering of neutrons by most materials is low. Therefore the samples investigated by neutrons are much larger, usually single crystals of a few $\mathrm{mm}^{3}$ and powder samples of a few $\mathrm{cm}^{3}$ are used.

Several types of high-pressure cells for neutron diffraction studies have been built and are used both at nuclear reactors and at spallation sources. Generally, the cells for high-pressure neutron diffraction are large and in most cases adapted to varied-temperature environments. The main types of highpressure cells for neutrons are (i) gas-pressure cells, (ii) cylinder-and-piston cells, and (iii) opposed-anvils cells. In the gas pressure cell, the pressure is generated by a compressor outside the 'bomb' containing the sample and transmitted to it through a capillary (Paureau \& Vettier, 1975); a pressure of about $0.5 \mathrm{GPa}$ can be generated in these cells. The cylinderand-piston cells are bigger and usually driven by a hydraulic press (Mizuki \& Endoh, 1981; McWhan, 1984), but a higher pressure of about $3 \mathrm{GPa}$ can be obtained. The walls of the gas or liquid pressure-cell bombs and the cylinders are made of materials that scatter neutrons weakly: aluminium alloys, vanadium, $\mathrm{Ti}_{66} \mathrm{Zr}_{34}$ alloy (having zero scattering amplitude due to the opposite signs of scattering amplitudes of $\mathrm{Ti}$ and $\mathrm{Zr}$ ), and tungsten-carbide- or steel-supported $\mathrm{Al}_{2} \mathrm{O}_{3}$. The highest range of pressure is attainable in the opposed-anvils cells. Constructions of most of opposed-anvils cells for neutrons incorporate anvils with a recess in the centre to enclose a larger sample - so called Chechevitsa anvils (Stishov \& Popova, 1961); or toroid anvils, with toroid grooves in the anvils around the sample space (Khvostantsev et al., 1977, 2004). The anvils are made of tungsten carbide, and of sapphire or diamond for higher-pressure ranges. Single-crystal neutron diffraction measurements in the pressure approaching $40 \mathrm{GPa}$ were carried out (Glazkov et al., 1989), however the large diamond anvils used were prohibitively expensive. At present perhaps the most widely used is the so-called ParisEdinburgh cell, based on opposed toroid anvils and optimized for time-of-flight neutron diffraction in pulsed neutron sources (Besson et al., 1992), but also applied at synchrotrons for experiments where the X-ray beam passes through the gasket. A DAC has been applie in neutron diffraction studies too (Goncharenko, 2006).

\section{Strained crystals, molecules and atoms}

High pressure was applied to various compounds as simple as elements and as complex as proteins. The pressure-induced changes in the crystal structures are sometimes compared to those induced by temperature (Bujak \& Angel, 2006), isotopic 
replacement (Ichikawa, 1998; Goncharenko, 2005) or other effects, but no general relations can be drawn. Depending on the problem investigated, a different pressure range is applied. Relatively low pressures, of a few GPa, can modify the weakest interactions, like van der Waals forces. Thus molecular crystals are easily modified and a pressure of about 2 $3 \mathrm{GPa}$ can compress their volume to about $80 \%$. An example of the phase diagram of a molecular substance is shown in Fig. 13. It can be seen that phase diagrams presented in most text books on chemical physics and thermodynamics span a much lower range of pressure than that attainable in the DAC. In the typical $P-T$ diagrams determined with the aid of DAC, the gas phase and boiling curves are overlaid with the ordinate $T$ axis. On the other hand, these huge pressures are comparable to the intermolecular interactions in crystal structures. Molecular crystals are formed by a very large group of organic compounds and it has already been recognized that pressure is an efficient method of generating new polymorphs (Boldyreva, 1990, 2004; Allan et al., 1998; Allan \& Clark, 1999; Allan et al., 2002; Boldyreva, Shakhtshneider, Ahsbahs, Sowa \& Uchtmann, 2002; Boldyreva et al., 2003; Fabbiani et al., 2005; Podsiadło et al., 2005, 2006; Gajda et al., 2006; Gajda \& Katrusiak, 2007; Bujak et al., 2007) and binary systems characteristic for high-pressure conditions only (Loubeyre et al., 1993, 1994; Loubeyre, 1996; Kuhs, 2004). The higher the pressure, the further-reaching are the structural modifications. Thus the lowest pressures affect mainly the intermolecular contacts and molecular and ionic arrangements (Budzianowski \& Katrusiak, 2006b), higher pressure can change molecular conformation, and still higher pressure leads to chemical reactions, like polymerization (Kikegawa \& Iwasaki, 1983; Nicol \& Yin, 1984; Dziubek \& Katrusiak, 2004), and modify the electronic structure of atoms in elements and molecules (Fujii et al., 1989; Siringo et al., 1990; Chacham et al., 1992; Akahama et al., 1995; Mesot et al., 1995; Serra et al., 1998; Adler et al., 1999; Neaton \& Ashcroft, 1999; Goncharov et al., 2000; Eremets et al., 2000, 2001). Spectacular phase transitions and sequences of changing properties are observed, like those in compressed oxygen (Shimizu et al., 1998). In this respect, the pressure experiments are ideal for investigating intermolecular forces and their hierarchy (Budzianowski \& Katrusiak, 2006a; Budzianowski et al., 2006). On the other hand, pressure-induced transformations are difficult to predict. It was shown that even simple elements under pressure can undergo surprising transformations to structures where the atoms differentiate into a host and a guest network (Nelmes et al., 1999; McMahon et al., 2000). Pressure and temperature can also be used for inducing amorphous phases of various compounds (Yamanaka et al., 2001) or for investigating properties of nanoparticles (Palosz et al., 2004).

\section{Conclusions}

Over the last 50 years, high-pressure crystallography has evolved from infancy, associated with large, costly and often dangerous instrumentation, into a neat, safe, relatively cheap and powerful technique, already diversified for various specific applications. Most of this progress is due to the diamond-anvil cell (DAC), this year celebrating the half-century anniversary of its inception. The increased application of high pressures in structural analysis has been possible owing to other inventions and developments in diffraction instrumentation and methodology, such as powerful computers, automatic diffractometers, two-dimensional detectors, highly efficient

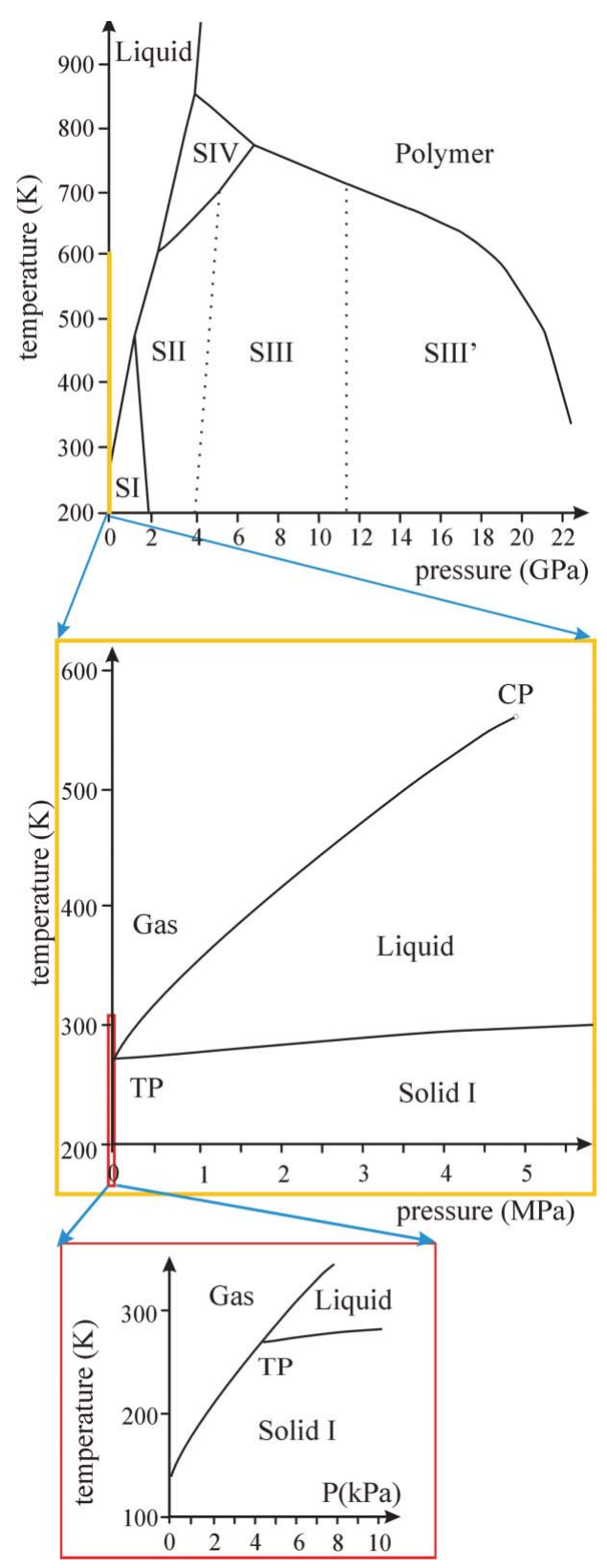

Figure 13

Phase diagram of benzene, $\mathrm{C}_{6} \mathrm{H}_{6}$, (top); its yellow-marked part expanded 4000 times (centre) along the pressure axis, to show the boiling curve ending with critical point (CP); and (bottom) the diagram with pressure scale enhanced 300 times further to illustrate the sublimation curve and the triple point (TP, at $4.785 \mathrm{kPa}$ and $278.7 \mathrm{~K}$ ). The diagrams have been drawn to scale: note the change in pressure units ( $\mathrm{GPa} v s \mathrm{MPa}$ and $\mathrm{kPa}$ ). The dotted lines (top diagram) mark phase boundaries not confirmed structurally. 
methods of structure solution and refinement etc. Thanks to all this progress, today it is possible to perform in a laboratory structural determinations on crystals of minerals, ionic and organic compounds, and even proteins; for specific cases, with an accuracy comparable to that of results of measurements on bare crystals. In synchrotron facilities, elastic and inelastic scattering can be measured at extreme pressures and temperatures on short time scales, and structures of much more complex crystals determined. Neutron diffraction experiments can be carried out to about $40 \mathrm{GPa}$ (Goncharenko, 2006).

The development of high-pressure methodology continues. One can envisage several directions of improvement in the area of high-pressure X-ray diffractometry in laboratories. Brighter X-ray sources will be required for quicker data collections on smaller samples enclosed in the DAC - thus higher pressures and more precise results will be attainable in laboratories. High-pressure measurements would be considerably facilitated by fully automatic procedures for DAC centring on diffractometers, fully automatic analysis of diffraction images eliminating coincidences with diamond reflections and simultaneous diffraction events, automatic data reduction incorporating all corrections determined from photographs of the pressure chamber, new efficient methods for pressure calibration and complementary spectroscopic analyses that could be performed 'on-line' with the diffraction experiment, or availability of cheap larger diamond anvils to increase the table/culet surface ratio and build better DAC's capable of reaching higher pressures automatically in preprogrammed steps. With all these and other, currently not conceivable, developments in the equipment and methods, accompanied by a financial incentive for the commercial suppliers of diffractometers generated by increased demand, the thermodynamic parameter of pressure can become as common in structural analysis as temperature or composition.

In certain respects, high-pressure structural experiments are more convenient than those at low temperature. First of all, it is possible to generate pressure away from the diffractometer, and then the compressed crystal can be investigated by spectroscopic and diffractometric methods and practically stored indefinitely in the DAC. This saves diffractometer time when single crystals are grown in situ at elevated pressures. When crystals are grown in the DAC, one can choose between isothermal, isochoric and isobaric (at $0.1 \mathrm{MPa}$ ) crystallization, and it is possible to adjust two thermodynamic parameters, $T$ and $P$, to any required value. The process of crystal growth is most efficient close to the melting conditions, and one can move along the melting curve by adjusting pressure and temperature. Close to the melting curve, we have observed a 'self-healing' process, when faults in the faces of grown crystals spontaneously repair. A single crystal fully filling the highpressure chamber is usually grown in an hour, and the healing of faults requires halting the process (of increasing pressure or lowering temperature) for minutes. The crystallization in the DAC can be further modified by adding solvents and conducting isochoric or isothermal freezing (van Valkenburg et al., 1971; Fabbiani et al., 2005; Budzianowski \& Katrusiak, 2006b). The high-pressure equipment and methodology for crystallographic studies are constantly being developed. Already structural results of high-pressure determinations constitute a large database enormously contributing to all materials sciences. For the last 50 years, high-pressure studies of crystals have become the common element of research in $\mathrm{X}$-ray and neutron laboratories, and the number of crystallographers employing high pressures and the scope of problems tackled by high-pressure techniques are expected to continue to increase.

Helpful discussions and preparation of photographs presented in Figs. 6, 7 and 8 by Mr K. Dziubek and Mr M. Podsiadło are gratefully acknowledged. This report was partly supported by the Polish Ministry of Science and High Education, Grant NN204 195633.

\section{References}

Adler, P., Schwarz, U., Syassen, K, Rozenberg, G. Kh., Machavariani, G. Yu., Milner, A. P., Pasternak, M. P. \& Hanfland, M. (1999). Phys. Rev. B, 60, 4609-4617.

Ahsbahs, H. (1987). Prog. Cryst. Growth Charact. 14, 263-302.

Ahsbahs, H. (2004). Z. Kristallogr. 219, 305-308.

Akahama, Y., Kawamura, H., Haeuserman, D., Hanfland, M. \& Shimomura, O. (1995). Phys. Rev. Lett. 74, 4690-4693.

Allan, D. R. \& Clark, S. J. (1999). Phys. Rev. Lett. 82, 3464-3467.

Allan, D. R., Clark, S. J., Brugmans, M. J. P., Ackland, G. J. \& Vos, W. L. (1998). Phys. Rev. B, 58, 11809-11812.

Allan, D. R., Clark, S. J., Dawson, A., McGregor, P. A. \& Parsons, S. (2002). Acta Cryst. B58, 1018-1024.

Allan, D. R., Clark, S. J., Parsons, S. \& Ruf, M. (2000). J. Phys. Condens. Matter, 12, L613-L618.

Angel, R. J. (1993). J. Phys. Condens. Matter, 5, L141-L144.

Angel, R. J. (2004). J. Appl. Cryst. 37, 486-492.

Angel, R. J., Allan, D. R., Miletich, R. \& Finger, L. W. (1997). J. Appl. Cryst. 30, 461-466.

Angel, R. J., Bujak, M., Zhao, J., Gatta, G. D. \& Jacobsen, S. D. (2007). J. Appl. Cryst. 40, 26-32.

Angel, R. J., Downs, R. T. \& Finger, L. W. (2000). Rev. Mineral. Geochem. 41, 559-596.

Barciszewski, J., Jurczak, J., Porowski, S., Specht, T. \& Erdmann, V. A. (1999). Eur. J. Biochem. 260, 293-307.

Barnett, J. D., Block, S. \& Piermarini, G. J. (1975). Rev. Sci. Intrum. 44, 3144-3150.

Bell, P. M., Xu, J. A. \& Mao, H. K. (1986). Shock Waves in Condensed Matter, edited by Y. M. Gupta, pp. 125-130. New York: Plenum Press.

Bertani, R., Mali, M., Roos, J. \& Brinkmann, D. (1990). J. Phys. Condens. Matter, 2, 7911-7923.

Bertani, R., Mali, M., Roos, J. \& Brinkmann, D. (1992). Rev. Sci. Instrum. 63, 3303-3306.

Besson, J. M., Nelmes, R. J., Hamel, G., Loveday, J. S., Weil, G. \& Hull, S. (1992). Physica (Utrecht), B180, 907-910.

Birch, F. (1986). J. Geophys. Res. 91, 4949-4954.

Bloch, D. \& Voiron, J. (1984). Condensed Matter Research Using Neutrons, edited by S. W. Loversey \& R. Scherm, NATO ASI Series $B$, Vol. 112, pp. 39-62. New York: Plenum.

Block, S., Weir, C. E. \& Piermarini, G. J. (1965). Science, 148, 947-948.

Boehler, R. (2006). Rev. Sci. Instrum. 77, 115103.

Boehler, R. \& De Hantsetters, K. (2004). High Press. Res. 24, 391-396.

Boldyreva, E. V. (1990). React. Solids, 8, 269-282. 
Boldyreva, E. V. (2004). High-Pressure Crystallography, edited by A. Katrusiak \& P. F. McMillan, pp. 495-512. Dordrecht: Kluwer Academic Publishers.

Boldyreva, E. V., Ahsbahs, H. \& Weber, H.-P. (2003). Z. Kristallogr. 218, 231-236.

Boldyreva, E. V., Shakhtshneider, T. P., Ahsbahs, H., Sowa, H. \& Uchtmann, H. (2002). J. Thermal Anal. Calorim. 66, 437-452.

Boldyreva, E. V., Shakhtshneider, T. P., Ahsbahs, H., Uchtmann, H., Burgina, E. B. \& Baltakhinov, V. P. (2002). Pol. J. Chem. 76, 1333-1346.

Brash, J. W. (1965a). Spectrochim. Acta, 21, 1183-1188.

Brash, J. W. (1965b). J. Chem. Phys. 43, 3473-3476.

Brazhkin, V. V., Lyapin, A. G. \& Hemley, R. J. (2002). Philos. Mag. 82, 231-253.

Bridgman, P. W. (1937). Proc. Am. Acad. Arts Aci. 71, 387-460.

Bridgman, P. W. (1949). The Physics of High Pressure. London: Bell and Sons.

Bridgman, P. W. (1950). Proc. R. Soc. London Ser. A, 203, 1-17.

Bridgman, P. W. (1952). Proc. Am. Acad. Arts Aci. 81, 167-251.

Budzianowski, A. \& Katrusiak, A. (2004). High-Pressure Crystallography, edited by A. Katrusiak \& P. F. McMillan, pp. 101-112. Dordrecht: Kluwer Academic Publishers.

Budzianowski, A. \& Katrusiak, A. (2006a). Acta Cryst. B62, 94-101.

Budzianowski, A. \& Katrusiak, A. (2006b). J. Phys. Chem. B, 110, 9755-9758.

Budzianowski, A., Olejniczak, A. \& Katrusiak, A. (2006). Acta Cryst. B62, 1078-1089.

Bujak, M. \& Angel, R. J. (2006). J. Phys. Chem. B, 110, 10322-10331.

Bujak, M., Budzianowski, A. \& Katrusiak, A. (2004). Z. Kristallogr. 219, 573-579.

Bujak, M., Dziubek, K. \& Katrusiak, A. (2007). Acta Cryst. B63, 124-131.

Bujak, M. \& Katrusiak, A. (2004). Z. Kristallogr. 219, 669-674.

Busing, W. R. \& Levy, H. A. (1967). Acta Cryst. 22, 457-464.

Chacham, H., Zhu, X. \& Louie, S. G. (1992). Phys. Rev. B, 46, 6688-6699.

Chervin, J. C., Canny, B., Besson, J. M. \& Pruzan, P. (1995). Rev. Sci. Instrum. 66, 2595-2598.

Chervin, J. C., Power, Ch. \& Polian, A. (2005). High Press. Res. 25, 97-105.

Crichton, W. A. \& Mezouar, Z. (2004). High-Pressure Crystallography, edited by A. Katrusiak \& P. F. McMillan, pp. 113-130. Dordrecht: Kluwer Academic Publishers.

Dadashev, A., Pasternak, M. P., Rozenberg, G. Kh. \& Taylor, R. D. (2001). Rev. Sci. Instrum. 72, 2633-2637.

Datchi, F., LeToullec, R. \& Loubeyre, P. (1997). J. Appl. Phys. 81, 3333-3339.

Dawson, A., Allan, D. R., Parsons, S. \& Ruf, M. (2004). J. Appl. Cryst. 37, 410-416.

Denner, W., Schulz, H. \& d'Amour, H. (1978). J. Appl. Cryst. 11, 260-264.

Dera, P. \& Katrusiak, A. (1999). J. Appl. Cryst. 32, 510-515.

Dunstan, D. J. (1989). Rev. Sci. Instrum. 60, 3789-3795.

Dunstan, D. J. \& Spain, I. L. (1989). J. Phys. E Sci. Instrum. 22, 913-923.

Dyadin, Y. A., Aladko, E. Y., Udachin, K. A. \& Tkacz, M. (1994). Pol. J. Chem. 68, 343-348.

Dziubek, K. F. \& Katrusiak, A. (2004). J. Phys. Chem. B, 108, 19089-19092.

Dziubek, K. F., Podsiadlo, M. \& Katrusiak, A. (2007). J. Am. Chem. Soc. 129, 12620-12621.

Edvards, P. P. \& Hensel, F. (1997). Nature (London), 388, 621-622.

Eremets, M. I. (1996). High Pressure Experimental Methods. Oxford University Press.

Eremets, M. I., Gregoryanz, E. A., Struzhkin, V. V., Mao, H.-K. \& Hemley, R. J. (2000). Phys. Rev. Lett. 85, 2797-2800.

Eremets, M. I., Hemley, R. J., Mao, H.-K. \& Gregoryanz, E. (2001). Nature (London), 411, 170-174.
Fabbiani, F. P. A., Allan, D. R., Parsons, S. \& Pulham, C. R. (2005). CrystEngComm, 7, 179-186.

Fabbiani, F. P. A. \& Pulham, C. R. (2006). Chem. Soc. Rev. 35, 932-942.

Finger, L. W. \& King, H. E. (1978). Am. Mineral. 63, 337-342.

Fiquet, G. \& Andrault, D. (1999). J. Synchrotron Rad. 6, 81-86.

Forman, R. A., Piermarini, G. J., Barnett, J. D. \& Block, S. (1972). Science, 176, 284-285.

Fourme, R. (1968). J. Appl. Cryst. 1, 23-30.

Fourme, R., Girard, E., Kahn, R., Ascone, I., Mezouar, M., Lin, T. \& Johnson, J. E. (2004). High-Pressure Crystallography, edited by A. Katrusiak \& P. F. McMillan, pp. 537-542. Dordrecht: Kluwer Academic Publishers.

Fujii, Y., Hase, K., Ohishi, Y., Fujihisa, H., Hamaya, N., Takemura, K., Shimomura, O., Kikegawa, T., Amemiya, Y. \& Matsushita, T. (1989). Phys. Rev. Lett. 63, 536-539.

Gajda, R., Dziubek, K. \& Katrusiak, A. (2006). Acta Cryst. B62, 86-93.

Gajda, R. \& Katrusiak, A. (2007). Acta Cryst. B63, 111-117.

Gauzzi, A., Gilioli, E., Licci, F., Prodi, A., Bolzoni, F., Marezio, M., Massidda, S., Bernardini, F., Continenza, A. \& Radaelli, P. G. (2004). High-Pressure Crystallography, edited by A. Katrusiak \& P. F. McMillan, pp. 429-446. Dordrecht: Kluwer Academic Publishers.

Girard, E., Dhaussy, A.-C., Couzinet, B., Chervin, J.-C., Mezouar, M., Kahn, R., Ascone, I. \& Fourme, R. (2007). J. Appl. Cryst. 40, 912-918.

Glazkov, V. P., Goncharenko, I. N., Irodova, V. A., Somenkov, V. A., Shilstein, S. S., Besedin, S. P., Makarenko, I. N. \& Stishov, S. M. (1989). J. Phys. Chem. 163, 509-514.

Goncharenko, I. N. (2004). High-Pressure Crystallography, edited by A. Katrusiak \& P. F. McMillan, pp. 321-340. Dordrecht: Kluwer Academic Publishers.

Goncharenko, I. N. (2005). Phys. Rev. Lett. 94, 20571.

Goncharenko, I. N. (2006). Acta Cryst. A62, s95.

Goncharov, A. F., Gregoryanz, E., Mao, H.-K., Liu, Z. \& Hemley, R. J. (2000). Phys. Rev. Lett. 85, 1262-1265.

Gruner, S. M. (2004). High-Pressure Crystallography, edited by A. Katrusiak \& P. F. McMillan, pp. 543-556. Dordrecht: Kluwer Academic Publishers.

Hamilton, W. C. (1974). International Tables for X-ray Crystallography, Vol. IV, pp. 273-284. Birmingham: Kynoch Press.

Hazen, R. M. \& Finger, L. W. (1982). Comparative Crystal Chemistry. New York: John Wiley and Sons.

Hemley, R. J. (1998). Science, 281, 1296-1297.

Hemley, R. J. \& Ashcroft, N. W. (1998). Phys. Today, 51, 26-32.

Holzapfel, W. B. \& Isaacs, N. I. (1997). High-Pressure Techniques in Chemistry and Physics. Oxford University Press.

Hostettler, M. \& Schwarzenbach, D. (2005). C. R. Chim. 8, 147-156.

Huppertz, H. (2004). Z. Kristallogr. 219, 330-338.

Ichikawa, M. (1998). Pol. J. Chem. 72, 230-240.

Jackson, S. M., Nield, V. M., Whitworth, R. W., Oguro, M. \& Wilson, C. C. (1997). J. Phys. Chem. B, 101, 6142-6145.

Jamieson, J. C. (1957). J. Geol. 65, 334-343.

Jamieson, J. C., Lawson, A. W. \& Nachtrieb, N. D. (1959). Rev. Sci. Instrum. 30, 1016-1019.

Jayaraman, A. (1983). Rev. Mod. Phys. 55, 65-108.

Kabalkina, S. S. \& Troitskaya, Z. V. (1961). J. Struct. Chem. 2, 22-26.

Kabalkina, S. S. \& Vereshchagin, L. F. (1960). Dokl. Acad. Sci. USSR, 131, 300-302.

Katrusiak, A. (1999). J. Appl. Cryst. 32, 1021-1023.

Katrusiak, A. (2001). Z. Kristallogr. 216, 646-647.

Katrusiak, A. (2004a). High-Pressure Crystallography, edited by A. Katrusiak \& P. F. McMillan, pp. 57-68. Dordrecht: Kluwer Academic Publishers.

Katrusiak, A. (2004b). Z. Kristallogr. 219, 461-467.

Katrusiak, A. (2004c). Acta Cryst. A60, 409-417. 
Katrusiak, A. \& Dauter, Z. (1996). Acta Cryst. D52, 607-608.

Katrusiak, A. \& McMillan, P. F. (2004). Editors. High-Pressure Crystallography. Dordrecht: Kluwer Academic Publishers.

Kawada, S. (1972). J. Phys. Soc. Jpn, 32, 1442.

Keller, R. \& Holzapfel, W. B. (1977). Rev. Sci. Instrum. 48, 512.

Khvostantsev, L. G., Slesarev, V. N. \& Brazhkin, V. V. (2004). High Press. Res. 24, 371-383.

Khvostantsev, L. G., Vereshchagin, L. F. \& Novikov, A. P. (1977). High Temp. High Press. 9, 637-639.

Kikegawa, T. \& Iwasaki, H. (1983). Acta Cryst. B39, 158-164.

King, H. E. \& Finger, L. W. (1979). J. Appl. Cryst. 12, 374-378.

Kim, E., Pang, T., Utsumi, W., Solozhenko, V. L. \& Zhao, Y. (2007). Phys. Rev. B, 75, 18418.

Klug, D. D. \& Whalley, E. (1983). Rev. Sci. Instrum. 54, 1205-1208.

Konno, M., Okamoto, T. \& Shirotani, I. (1989). Acta Cryst. B45, 142-147.

Kuhs, W. F. (2004). High-Pressure Crystallography, edited by A. Katrusiak \& P. F. McMillan, pp. 475-494. Dordrecht: Kluwer Academic Publishers.

Kuhs, W. F., Bauer, F. C., Hausmann, R., Ahsbahs, H., Doewarth, R. \& Hoelzer, K. (1996). High Press. Res. 14, 341-352.

Kundrot, C. E. \& Richards, F. M. (1986). J. Appl. Cryst. 19, 208-213.

Kunz, M. (2001). Phase Transformations in Materials, edited by G. Kostorz, pp. 655-696. Weinheim: Wiley-VCH.

Lacam, A. \& Chateau, C. (1989). J. Appl. Phys. 66, 366-372.

Lawson, A. W. \& Tang, T. Y. (1950). Rev. Sci. Instrum. 21, 815.

Lee, H.-S, Luszczycki, K., Norberg, R. E. \& Conradi, M. S. (1987). Rev. Sci. Instrum. 58, 415-417.

Leger, J. M., Chateau, C. \& Lacam, A. (1990). J. Appl. Phys. 68, 2351-2354.

Line, C. M. B. \& Whitworth, R. W. (1996). J. Chem. Phys. 104, 10008-10013.

Lobban, C., Finney, J. L. \& Kuhs, W. F. (1997). Nature (London), 391, 268-270.

Loubeyre, P. (1996). High Press. Res. 14, 353-361.

Loubeyre, P., Jean-Louis, M., LeToullec, R. \& Charon-Gérard, L. (1993). Phys. Rev. Lett. 70, 178-181.

Loubeyre, P., LeToullec, R. \& Pinceaux, J.-P. (1994). Phys. Rev. Lett. 72, 1360-1363.

Loveday, J. S., McMahon, M. I. \& Nelmes, R. J. (1990). J. Appl. Cryst. 23, 392-396.

McMahon, M. I. (2004). High-Pressure Crystallography, edited by A. Katrusiak \& P. F. McMillan, pp. 1-20. Dordrecht: Kluwer Academic Publishers.

McMahon, M. I., Bovornratanaraks, T., Allan, D. R., Belmonte, S. A. \& Nelmes, R. J. (2000). Phys. Rev. B, 61, 3135-3138.

McWhan, D. B. (1984). Rev. Phys. Appl. 19, 715-718.

Malinowski, M. (1987). J. Appl. Cryst. 20, 379-382.

Mao, H.-K. \& Bell, P. M. (1978). Science, 102, 1145-1147.

Mao, H.-K., Jephcoat, A. P., Hemley, R. J., Finger, L. W., Zha, C. S., Hazen, R. M. \& Cox, D. E. (1988). Science, 239, 1131-1134.

Meade, C. \& Jeanloz, R. (1990). Rev. Sci. Instrum. 61, 2571-2580.

Merrill, L. \& Bassett, W. A. (1974). Rev. Sci. Instrum. 45, 290-294.

Mesot, J., Medarde, M., Rosenkranz, S., Fisher, P., Lacorre, P. \& Gobrecht, K. (1995). High Press. Res. 14, 35-40.

Miletich, R., Allan, D. R. \& Kuhs, W. F. (2000). Rev. Mineral. Geochem. 41, 445-519.

Mizuki, J. \& Endoh, Y. (1981). J. Phys. Soc. Jpn, 50, 914-919.

Neaton, J. B. \& Ashcroft, N. W. (1999). Nature (London), 400, 141-144.

Nelmes, R. J., Allan, D. R., McMahon, M. I. \& Belmonte, S. A. (1999). Phys. Rev. Lett. 83, 4081-4084.

Nelmes, R. J., Hatton, P. D., McMahon, M. I., Piltz, R. O., Crain, J., Cernik, R. J. \& Dushnell-Wye, G. (1992). Rev. Sci. Instrum. 63, 1039-1042.
Nicol, M. \& Yin, G. Z. (1984). J. Phys. Colloque C8, 48, 163-172.

Palosz, B., Stel'makh, S., Grzanka, E., Gierlotka, S., Pielaszek, R., Bismayer, U., Werner, S. \& Palosz, W. (2004). J. Phys. Condens. Matter, 16, S353-S377.

Parise, J. B. (2004). High-Pressure Crystallography, edited by A. Katrusiak \& P. F. McMillan, pp. 101-112. Dordrecht: Kluwer Academic Publishers.

Pasternak, M. P., Rozenberg, G. Kh., Xu, W. M. \& Taylor, R. D. (2004). High-Pressure Crystallography, edited by A. Katrusiak \& P. F. McMillan, pp. 311-320. Dordrecht: Kluwer Academic Publishers.

Pauling, L. (1939). The Nature of the Chemical Bond and the Structure of Molecules and Crystals. Cornell University Press.

Paureau, J. \& Vettier, C. (1975). Rev. Sci. Instrum. 64, 1484-1488.

Piermarini, G. J. (2001). J. Res. Natl Inst. Stand. Technol. 106, 889-920.

Piermarini, G. J. \& Block, S. (1975). Rev. Sci. Instrum. 46, 973-979.

Piermarini, G. J., Block, S. \& Barnett, J. D. (1973). J. Appl. Phys. 44, 5377-5382.

Piermarini, G. J., Block, S., Barnett, J. D. \& Forman, R. A. (1975). J. Appl. Phys. 46, 2774-2780.

Piltz, R. O., McMahon, M. I., Crain, J., Hatton, P. D., Nelmes, R. J., Cernik, R. J. \& Bushnell-Wye, G. (1992). Rev. Sci. Instrum. 63, 700-703.

Podsiadło, M., Dziubek, K. \& Katrusiak, A. (2005). Acta Cryst. B61, 595-600.

Podsiadło, M., Dziubek, K., Szafrański, M. \& Katrusiak, A. (2006). Acta Cryst. B62, 1090-1098.

Prewitt, C. T., Coppens, P., Phillips, J. C. \& Finger, L. W. (1987). Science, 238, 312-318.

Schiferl, D. (1977). Rev. Sci. Instrum. 58, 1316-1317.

Seal, M. (1984). High Temp. High Press. 16, 573-579.

Serra, S., Chiarotti, G., Scandolo, S. \& Tosatti, E. (1998). Phys. Rev. Lett. 80, 5160-5163.

Shimizu, H., Kumazaki, T., Kume, T. \& Sasaki, S. (2002). J. Phys. Chem. B, 106, 30-33.

Shimizu, K., Suhara, K., Ikumo, M., Eremets, M. I. \& Amaya, K. (1998). Nature (London), 393, 767-768.

Shimomura, O., Takemura, K., Fujihisa, H., Fujii, Y., Ohishi, Y., Kikegawa, T., Amemiya, Y. \& Matsushita, T. (1992). Rev. Sci. Instrum. 63, 967-972.

Shobu, T., Noda, Y., Iwasa, K., Hannan, A., Koghi, M., Ishimatsu, N. \& Shimomura, O. (2001). J. Phys. Soc. Jpn, 70, 1162-1163.

Siringo, F., Pucci, R. \& March, N. H. (1990). High Press. Res. 2 , 109-134.

Somenkov, V. A. (2005). J. Phys. Condens. Matter, 17, S2991-S3003.

Stishov, S. M. \& Popova, S. V. (1961). Geokhimiya, 10, 923-926.

Struzhkin, V. V., Hemley, R. J., Mao, H.-K. \& Timofeev, Yu. A. (1997). Nature (London), 390, 382-384.

Tkacz, M. \& Drickamer, H. G. (1986). J. Chem. Phys. 85, 1184-1189.

Valkenburg, A. van (1962). Rev. Sci. Instrum. 33, 1462.

Valkenburg, A. van, Mao, H.-K. \& Bell, P. M. (1971). Carnegie Inst. Washington Yearb. 70, 237-238.

Voiron, J. \& Vettier, C. (1987). High Pressure Chemistry and Biochemistry, edited by R. van Eldik \& J. Jonas, pp. 237-262. Dordrecht: Reidel.

Weir, C. E., Lippincott, E. R., van Valkenburg, A. \& Bunting, E. N. (1959). J. Res. Natl Bur. Stand. Technol. 63A, 55-62.

Yagi, T. (1985). J. Phys. Chem. Solids, 39, 563-571.

Yamanaka, T., Fukuda, T., Hattori, T. \& Sumiya, Y. (2001). Rev. Sci. Instrum. 72, 1458-1462.

Yamanaka, T., Nagai, T. \& Tsuchiya, T. (2001). Z. Kristallogr. 212, 401-462.

Yousuf, M. \& Rajan, K. G. (1982). Pramana, 18, 1-15. 